Cornell University Law School Scholarship@Cornell Law: A Digital Repository

$3-2015$

\title{
Addressing the Zeros Problem: Regression Models for Outcomes with a Large Proportion of Zeros, with an Application to Trial Outcomes
}

Theodore Eisenberg

Cornell Law School (deceased)

Thomas Eisenberg

Cornell University

Martin T. Wells

Cornell University,mtw1@cornell.edu

Min Zhang

Purdue University

Follow this and additional works at: https://scholarship.law.cornell.edu/facpub

Part of the Statistical Methodology Commons, and the Statistical Models Commons

\section{Recommended Citation}

Eisenberg, Theodore and Eisenberg, Thomas and Wells, Martin T. and Zhang, Min, "Addressing the Zeros Problem: Regression Models for Outcomes with a Large Proportion of Zeros, with an Application to Trial Outcomes," 12 Journal of Empirical Legal Studies $161-186(2015)$

This Article is brought to you for free and open access by the Faculty Scholarship at Scholarship@Cornell Law: A Digital Repository. It has been accepted for inclusion in Cornell Law Faculty Publications by an authorized administrator of Scholarship@Cornell Law: A Digital Repository. For more information, please contact jmp8@cornell.edu. 


\title{
Addressing the Zeros Problem: Regression Models for Outcomes with a Large Proportion of Zeros, with an Application to Trial Outcomes
}

\author{
Theodore Eisenberg, Thomas Eisenberg, Martin T. Wells, and Min Zhang*
}

\begin{abstract}
In law-related and other social science contexts, researchers need to account for data with an excess number of zeros. In addition, dollar damages in legal cases also often are skewed. This article reviews various strategies for dealing with this data type. Tobit models are often applied to deal with the excess number of zeros, but these are more appropriate in cases of true censoring (e.g., when all negative values are recorded as zeros) and less appropriate when zeros are in fact often observed as the amount awarded. Heckman selection models are another methodology that is applied in this setting, yet they were developed for potential outcomes rather than actual ones. Two-part models account for actual outcomes and avoid the collinearity problems that often attend selection models. A two-part hierarchical model is developed here that accounts for both the skewed, zero-inflated nature of damages data and the fact that punitive damage awards may be correlated within case type, jurisdiction, or time. Inference is conducted using a Markov chain Monte Carlo sampling scheme. Tobit models, selection models, and two-part models are fit to two punitive damage awards data sets and the results are compared. We illustrate that the nonsignificance of coefficients in a selection model can be a consequence of collinearity, whereas that does not occur with two-part models.
\end{abstract}

\section{INTRODUCTION}

Many legal system and other social science outcomes raise the question of how to model phenomena with multiple zeros. Trial outcomes generally result in verdicts for plaintiffs or defendants. A verdict for a plaintiff in an action involving money damages will lead to a positive award. A verdict for a defendant will lead to a zero award. For some purposes, the

\footnotetext{
*Address correspondence to Martin T. Wells, email: mtw1@cornell.edu. Theodore Eisenberg was Henry Allen Mark Professor, Cornell Law School and Adjunct Professor of Statistical Sciences, Cornell University; Thomas Eisenberg is a gradate student, Department of Economics, Cornell University; Wells is Charles A. Alexander Professor of Statistical Sciences, Professor of Biostatistics and Epidemiology, Weill Medical College, and Elected Member of the Law Faculty, Cornell University; Zhang is Associate Professor Department of Statistics, Purdue University.

Earlier versions of this material were presented at the First Annual Conference on Empirical Legal Studies, University of Texas and the International Conference on Empirical Legal Studies, conducted by the Cegla Center for Interdisciplinary Research of the Law, Tel Aviv University, Buchmann Faculty of Law.
} 
mass of zeros represented by defendant victories need not be accounted for. The research question of interest might be, conditional on plaintiff winning at trial, how much was recovered? In that case, the zero-award outcomes representing defendant trial wins might be ignored.

If, however, the researcher wished to include defendant wins in the analysis, ignoring the zero-award outcomes would not be satisfactory. This might be the case if one were computing the expected value of a possible lawsuit and wanted to account for both the probability of winning and the amount of any monetary award if the plaintiff prevailed. Similarly, if one were interested in the amount of punitive damages awarded to a plaintiff who won at trial and received a punitive damages award, the cases with punitive damages awards of zero could be excluded. But if one were interested in the expected punitive damages recovery in cases won by plaintiffs, it would be necessary to include the cases in which punitive damages awards were zero in cases won by plaintiffs.

Many empirical legal researchers realize that simple ordinary least squares methods may be unsatisfactory in the presence of many observations for which the dependent variable equals zero. Tobit models often are regarded as appropriate when data have a lower boundary of zero to avoid possibly biased and inconsistent ordinary least squares estimates (Tobin 1958). A common approach in the presence of many zero values is therefore to use Tobit models, which account for censoring of the dependent variable (e.g., De Ruijter \& Braat 2008; Fehr \& Gächter 2000; Hersch \& Viscusi 2004). A possible problem is that Tobit models do not account for the skewed, zero-inflated nature of damages data. Tobit models assume censoring of the dependent variable rather than the dependent variable often being observably equal to zero. This article reviews techniques for modeling skewed damages awards in the presence of many zero values. This article develops a two-part hierarchical model that accounts for the skewed, zero-inflated, and clustered nature of damages data. It compares the results of the Tobit, selection, and two-part models for two punitive damages data sets.

The underlying topics and statistical models that are discussed in this article have appeared in various econometric and statistics literatures. Each of the models we discuss below makes implicit distributional assumptions that need to be understood and validated. The goal of this article is to give an overview of the statistical models and issues that face a legal researcher when analyzing data with many zeros. The rest of the article is organized as follows. Section II reviews various models for analyzing data with a large proportion of the continuous outcome variable being zero. Section III applies the model to real data. We close the article with some discussion in Section IV and conclusions. The Appendix gives $R$ and OpenBugs code useful for fitting the two-part hierarchical model.

\section{Models for Analyzing a Continuous Outcome Variable with a Large Proportion of Zeros}

In empirical legal literature and other social science literature, there have been misunderstandings about the proper modeling of a continuous outcome variable with a large 
proportion of zeros. In this section we will discuss three classes of models and give some recommendations about their relevance to modeling trial outcomes.

In some data sets we do not observe outcome values above or below a certain level, due to a censoring or truncation mechanism. To model the relation between the observed outcomes $Y$ and a set of explanatory variables $X$, we consider a latent variable $Y^{*}$ that is subject to censoring/truncation. We will consider models in which changes in $X$ affect the mean of $Y$ only through the effect of $X$ on the latent variable $Y^{*}$. Truncation occurs when some observations on both the dependent variable and regressors are lost, for example, if punitive award level is the outcome variable and only cases with a punitive award are included in the sample. In effect, truncation occurs when the sample data are drawn from only a subset of a larger population. In the context of regression analysis, an outcome $Y$ is censored when we observe $\boldsymbol{X}$ for all observations, but we only know the true value of $Y$ for a restricted range of observations. Values of $Y$ in a certain range are reported as a single value or there is significant clustering around a value, say 0 . For an uncensored $Y, Y^{*}$, the true value of $Y$ when the censoring mechanism is not applied. We typically have all the observations for $\{Y, X\}$, but not $\left\{Y^{*}, \boldsymbol{X}\right\}$. Clearly, truncation entails a greater loss of information than censoring.

Suppose the random (outcome) variable $Y^{*}$ has the normal distribution with mean $\mu$ and standard deviation $\sigma$, that is, $Y^{*} \sim N\left(\mu, \sigma^{2}\right)$. When a distribution is censored on the left, observations with values at or below $\tau$ are set to $\tau_{y}$, that is:

$$
\begin{array}{lll}
Y=Y^{*} & \text { if } & Y^{*}>\tau \\
Y=\tau, & \text { if } & Y^{*} \leq \tau .
\end{array}
$$

In this case, notice that $P($ censored $)=P\left(Y^{*} \leq \tau\right)=\Phi\left(\frac{\tau-\mu}{\sigma}\right)$ and $P($ not censored $)=$ $P\left(Y^{*}>\tau\right)=\Phi\left(\frac{\mu-\tau}{\sigma}\right)$ so that the mean of the censored variable $Y$ equals:

$$
\begin{aligned}
E[Y] & =P(\text { not censored }) \times \mathrm{E}[\mathrm{Y} \mid \mathrm{Y}>\tau]+\mathrm{P}(\text { censored }) \times \tau_{\mathrm{y}} \\
& =\Phi\left(\frac{\mu-\tau}{\sigma}\right)\left[\mu+\frac{\sigma \varphi\left(\frac{\tau-\mu}{\sigma}\right)}{1-\Phi\left(\frac{\tau-\mu}{\sigma}\right)}\right]+\Phi\left(\frac{\tau-\mu}{\sigma}\right) \tau_{y},
\end{aligned}
$$

where $\varphi(\cdot)$ and $\Phi(\cdot)$ are probability density and cumulative distribution functions of the standard normal distribution, respectively. In the special case of $\tau=\tau_{y}=0$, we have $E[Y]=\Phi\left(\frac{\mu}{\sigma}\right)\left[\mu+\sigma \lambda\left(\frac{\mu}{\sigma}\right)\right]$, where $\lambda(\cdot)=\varphi(\cdot) / \Phi(\cdot)$ is the inverse Mill's ratio.

The lognormal distribution is used to model continuous random quantities when the distribution is believed to be skewed, such as certain awards and income variables. A random variable $Y$ is said to have the lognormal distribution with parameters $\mu \in \mathbb{R}$ and $\sigma \in(0, \infty)$ if $\ln (Y)$ has the normal distribution with mean $\mu$ and standard deviation $\sigma$. 
Equivalently, $Y=e^{Z}$ where $Z$ is normally distributed with mean $\mu$ and standard deviation $\sigma$. If $Y$ has the lognormal distribution with parameters $\mu$ and $\sigma$, then the mean and variance of $Y$ are:

$$
E[Y]=\exp \left(\mu+\frac{1}{2} \sigma^{2}\right) \text { and } \operatorname{var}(Y)=\exp \left[2\left(\mu+\sigma^{2}\right)\right]-\exp \left(2 \mu+\sigma^{2}\right)
$$

The moments of a truncated lognormal random variable equals $E\left[Y^{k} \mid Y>a\right]=$ $\exp \left(k \mu+\frac{k^{2}}{2} \sigma^{2}\right) \Phi\left\{\left[k \sigma^{2}-(\ln a-\mu)\right] / \sigma\right\} / \Phi\{(\mu-\ln a) / \sigma\}$ for $k>0$. This definition of a lognormal random variable is in terms of the natural logarithm but other bases would lead to the same family of distributions, with rescaled parameters.

An easy diagnostic to determine if a lognormal distribution is needed, say with awards data, is to check if the mean award is well above the median award-if this is the case, there is a suggestion of a right-skewed distribution. A kernel density estimate (or histogram) of $\log$ awards can also be plotted and examined for approximate normality. Once the data reveal approximate normality of the logged outcomes, the decision to use logarithms rather than levels is clear-cut. A failure to plot the distributions of the levels and logs will likely lead to flawed analysis. Eisenberg and Wells (2006) give a methodological primer on various issues related to model selection for levels and logs in award data.

\section{A. The Tobit Model}

The standard Tobit model applies only if the underlying dependent variable contains negative values that have empirical realizations censored to the value zero. However, the Tobit model is routinely applied when the values of the observed dependent variable are exclusively nonnegative and are clustered at zero, irrespective of whether censoring has occurred.

In a probit model, the true outcome variable, $Y^{*}$, is unobserved (latent); what is really observed is an indicator variable, $Y$, which takes on the value of 1 if $Y^{*}$ is greater than zero, and 0 otherwise. In contrast, Tobin (1958) devised what became known as the Tobit (i.e., Tobin's probit) or censored normal regression model for situations in which $Y$ is observed for values greater than zero but is censored (not observed) for values of zero or less. In the standard Tobit model, the observed outcome $Y$ is related to the latent variable $Y^{*}$ by the rule:

$$
\begin{gathered}
Y_{i}^{*}=\beta^{\mathrm{T}} X_{\mathrm{i}}+\varepsilon_{\mathrm{i}} \quad \varepsilon_{\mathrm{i}} \sim \mathrm{N}\left(0, \sigma^{2}\right) \\
Y_{i}=Y_{i}^{*} \quad \text { if } \quad Y_{i}>0 \\
Y_{i}=0 \quad \text { if } \quad Y_{i}^{*} \leq 0,
\end{gathered}
$$

where $\boldsymbol{X}_{\boldsymbol{i}}$ is the collection of the independent variables, $\boldsymbol{\beta}$ is the vector of coefficients, and the $\varepsilon_{i}$ 's are assumed to be independently normally distributed. Therefore, in this model, $Y_{i}^{*}$ has normal distribution with mean $\boldsymbol{\beta}^{T} \boldsymbol{X}_{i}$ and standard deviation $\sigma$, that is, $Y_{i}^{*} \sim N\left(\boldsymbol{\beta}^{T} \boldsymbol{X}_{i}, \sigma^{2}\right)$. Note that observed zeros of the outcome variable can mean either a true zero or censored 
data. For this data structure it is known that ordinary least squares estimators are biased downward (Greene 2008). Maximum-likelihood estimation of $\boldsymbol{\beta}$ for the Tobit model is straightforward and widely available in statistics packages.

To interpret the Tobit model's regression parameter estimates, the marginal effects of the independent variables on some conditional mean function need to be examined. In the ordinary least squares model $Y_{i}=\boldsymbol{\beta}^{T} \boldsymbol{X}_{i}+\varepsilon_{i}, \mathcal{E}_{i} \sim N\left(0, \sigma^{2}\right)$, the conditional mean function is $E(Y \mid X)=\boldsymbol{\beta}^{T} \boldsymbol{X}$, and the marginal effect is $\partial E(Y \mid \boldsymbol{X}) / \partial \boldsymbol{x}_{j}=\beta_{j}$, where $x_{j}$ is the $j$ th independent variable. This makes interpretation clear-cut: $\beta_{j}$ measures the marginal effect of the $j$ th independent variable on $Y$. However, in the Tobit model, there are three different conditional means: those of the latent variable $Y^{*}$, the observed dependent variable $Y$, and the uncensored observed dependent variable $Y$ if $Y>0$. Interpretation depends on the quantity of interest. It can be shown using the properties of the truncated normal distribution in Equation (2) that $E[\boldsymbol{Y} \mid \boldsymbol{X}]=\Phi\left(\boldsymbol{\beta}^{T} \boldsymbol{X} / \sigma\right)\left[\boldsymbol{\beta}^{T} \boldsymbol{X}+\sigma \lambda\left(\boldsymbol{\beta}^{T} \boldsymbol{X} / \sigma\right)\right]$ and $E[Y \mid \boldsymbol{X}, Y>0]=E[Y \mid \boldsymbol{X}] /$ $P($ not censored $)=E[Y \mid \boldsymbol{X}] / \Phi\left(\boldsymbol{\beta}^{T} \boldsymbol{X} / \sigma\right)=\boldsymbol{\beta}^{T} \boldsymbol{X}+\sigma \lambda\left(\boldsymbol{\beta}^{T} \boldsymbol{X} / \sigma\right)$ so that the corresponding marginal effects equal $\partial E(Y \mid \boldsymbol{X}) / \partial x_{j}=\beta_{j} \Phi\left(\boldsymbol{\beta}^{T} \boldsymbol{X} / \sigma\right)$, and $\partial E(Y \mid \boldsymbol{X}, \quad Y>0) / \partial x_{j}=\beta_{j}\left\{1-\left[\lambda\left(-\boldsymbol{\beta}^{T} \boldsymbol{X} /\right.\right.\right.$ $\left.\sigma]\left[\lambda\left(-\boldsymbol{\beta}^{T} \boldsymbol{X} / \sigma\right)+\boldsymbol{\beta}^{T} \boldsymbol{X} / \sigma\right]\right\}$.

The development of the Tobit model depends on the normality assumption, which is not appropriate for skewed award data. If the models are in the log form, rather than level, that is, the conditional distribution of the latent variable $Y^{*}$ is now $\log$ normal with parameters $\boldsymbol{\beta}^{T} \boldsymbol{X}$ and $\sigma$. A primary benefit of the approaches discussed in the subsequent sections is that they are a more natural way than Tobit to log transform the model.

The Tobit model posits that the outcome variable is censored at zero. If no censoring has occurred, the standard Tobit specification is inappropriate. Maddala (1992:341) gives a warning against using the Tobit model when no censoring has occurred: "Every time we have some zero observations in the sample, it is tempting to use the Tobit model. However, it is important to understand what the model really says. What we have is a situation where $Y^{*}$ can, in principle, take on negative values. However, we do not observe them because of censoring. Thus the zero values are due to nonobservability. This is not the case with automobile expenditures, hours worked, or wages. These variables cannot, in principle, assume negative values. The observed zero values are due not to censoring, but due to the decisions of individuals." Consequently, if there has been no censoring, the Tobit model may give a misspecified model and the likelihood function used to construct the estimates is incorrect.

If there is no censoring and just the presence of zeros, the appropriate procedure would be to model the phenomena that produce the zero observations rather than to use a Tobit model. A debate over the propriety of using Tobit in corner-solution situations (as opposed to true censored variable situations) exists. One could perhaps rationalize this alternative view (Wooldridge 2010). One can view the latent variable as some decision process metric -one uses some evaluation method to determine the amount of damages that are worthy in this case. If the jury is very inclined to rule unfavorably, the scoring metric may indeed be negative. Of course, negative damages are not possible, so they are indeed set to zero. In other words, many of these situations where actual values are zero may still be viewed as censored variables considering that the latent variable deals with a related but different decision-making process. 
Tobit models have been applied in the empirical legal literature in the presence of actual zeros. For example, in a study of punitive damages, Hersch and Viscusi (2004) state that "[b]ecause of the large number of zero values for punitive damages, we use tobit regression." De Ruijter and Braat (2008) use a Tobit model with the dependent variables equal to the number of hours of co-working, which are limited by zero but are not censored. The models discussed in the next two subsections would provide more appropriate modeling strategies for both the Hersch and Viscusi (2004) and De Ruijter and Braat (2008) data analyses.

\section{B. The Selection Model}

The selection model has emerged as an alternative to Tobit when values cluster at zero due to selection rather than censoring. Applications of the selection model have proven problematic as well. The Tobit model was formulated to deal with estimation bias associated with censoring; the selection model (Heckman 1979) is a correction for selection bias, which arises when interest centers on the relationship between $X$ and $Y$ but data are available only for cases in which another variable exceeds a fixed certain value. The selection model, which contains the Tobit model as a special case, was designed as a correction for selection bias.

The selection model is governed by two equations. The first equation is a probit model for the probability of having a positive outcome, and the second equation is a linear model of the outcome among the subsample with $Y>0$, that is:

$$
\begin{array}{cl}
Y_{i}^{*(1)}=\alpha^{\mathrm{T}} \boldsymbol{X}_{1 \mathrm{i}}+\varepsilon_{1 \mathrm{i}} & \varepsilon_{1 \mathrm{i}} \sim \mathrm{N}(0,1) \\
Y_{i}^{*(2)}=\boldsymbol{\beta}^{T} \boldsymbol{X}_{2 i}+\varepsilon_{2 i} & \varepsilon_{2 i} \sim N\left(0, \sigma_{2}^{2}\right) \\
Y_{i}=Y_{i}^{*(2)} \quad \text { if } & Y_{i}^{*(1)}>0 .
\end{array}
$$

The explanatory variable sets $X_{1}$ and $X_{2}$ can be different subsets of $X$, subject to some identification conditions.

A key limitation to the Tobit model is that the probability of a positive value and the actual value, given that it is positive, are determined by the same underlying regression model. Both the selection model and the two-part model, discussed in the next subsection, specify separate parts to their model, one accounting for the probability of a positive outcome $P[Y>0 \mid \boldsymbol{X}]$ and the mean outcome conditional on $Y>0, E[Y \mid Y>0, \boldsymbol{X}]$. The sample selection model was developed to estimate $E\left[Y^{*(2)} \mid X\right]$. However, if one is interested in actual outcomes, the focus should be on $E[Y \mid X]$. It follows from Equation (2) and the model in Equation (5) that for selection model:

$$
E[Y \mid Y>0, \boldsymbol{X}]=\boldsymbol{\beta}^{\mathrm{T}} \boldsymbol{X}_{2}+\varrho \sigma_{2} \lambda\left(\boldsymbol{\alpha}^{\mathrm{T}} \boldsymbol{X}_{1}\right)
$$

The inverse Mills ratio $\lambda(\cdot)=\varphi(\cdot) / \Phi(\cdot)$ is used to estimate the $E\left[\varepsilon_{1} \mid Y>0, X\right]=$ $\varrho \sigma_{2} \lambda\left(\boldsymbol{\alpha}^{T} \boldsymbol{X}_{1}\right)$, where term $\left(\varepsilon_{1}, \varepsilon_{2}\right)$ has a bivariate normal distribution with mean equal to $(0$, 0 ) and covariance matrix $\Sigma$ : 


$$
\Sigma=\left(\begin{array}{lr}
1 & \varrho \sigma_{2} \\
\varrho \sigma_{2} & \sigma_{2}^{2}
\end{array}\right) .
$$

For the latent outcome $Y^{*(2)}, E\left[Y^{*(2)} \mid \boldsymbol{X}\right]=\boldsymbol{\beta}^{T} \boldsymbol{X}$, and for the observed (actual) outcomes $Y$, it follows that $E[Y \mid X]=\Phi\left(\alpha^{T} \boldsymbol{X}_{1}\right)\left[\boldsymbol{\beta}^{T} \boldsymbol{X}_{2}+\varrho \sigma_{2} \lambda\left(\boldsymbol{\alpha}^{T} \boldsymbol{X}_{1}\right)\right]$ and $E[Y \mid \boldsymbol{X}, Y>0]=\boldsymbol{\beta}^{T} \boldsymbol{X}_{2}+\varrho \sigma_{2} \lambda\left(\boldsymbol{\alpha}^{T} \boldsymbol{X}_{1}\right)$. The corresponding marginal effects can be calculated via differentiation of these expectations.

As with the Tobit model, the development of the selection model depends on the normality assumption, which is not appropriate for skewed award data. If the models are in the $\log$ form, rather than level, it is appropriate, that is, the conditional distribution of the latent variable $Y^{*}$ is now $\log$ normal with parameters $\boldsymbol{\beta}^{T} \boldsymbol{X}$ and $\sigma$. It follows from Equation (3) and some properties of the log normal distribution that $\left.E[Y \mid X]=\exp \left\{\boldsymbol{\beta}^{T} \boldsymbol{X}_{2}+\sigma_{2}^{2} / 2\right\} \Phi\left(\boldsymbol{\alpha}^{T} \boldsymbol{X}_{1}+\varrho^{2} \sigma_{2}^{2}\right)\right\}$. The corresponding marginal effects can be calculated via differentiation of these expectations.

The identification of the selection model can come from two different sources. The first is to use $\boldsymbol{X}$ (the instruments) in the selection by imposing the exclusion restriction assumption that some components of $X$ have coefficients set equal to zero. However, such exclusion assumptions are often untenable and are hard to defend, particularly in trial outcome data models for which the determinants of zero awards are often the same as the determinants of the amount of positive awards. In the absence of exclusion restrictions, the second potential source of identification is functional form. Another issue facing the selection model is that of multicollinearity since there is linear dependence between the columns of $\boldsymbol{X}$ and the inverse Mills coefficient. Since maximum-likelihood estimation is not numerically stable and is computationally cumbersome in the selection model and the estimates sometimes fails to converge, the Heckman (1979) two-step estimator is sometimes used to fit the models (e.g., Bushway et al. 2007).

\section{The Two-Part Model}

In trial outcome data, the actual outcome is fully observed and is not a latent variable. Zero values for damages indicate that zero dollars were awarded. If many observations have zero damages, then the statistical challenge is to model these outcomes. As long as the zero awards are true zeros and not missing data, there is no selection or censoring to address.

The two-part model is also governed by two equations. The first equation is a probit estimator of the probability of having a positive outcome and the second equation is a linear model of the outcome among the subsample with $Y>0$, that is:

$$
\begin{gathered}
Y_{i}^{*(1)}=\alpha^{\mathrm{T}} \boldsymbol{X}_{1 \mathrm{i}}+\varepsilon_{1 \mathrm{i}} \quad \varepsilon_{1 \mathrm{i}} \sim \mathrm{N}(0,1) . \\
Y_{i}^{*(2)} \mid Y_{i}^{*(1)}>0=\boldsymbol{\beta}^{T} \boldsymbol{X}_{2 i}+\varepsilon_{2 i} \quad \varepsilon_{2 i} \sim N\left(0, \sigma_{2}^{2}\right) \\
Y_{i}=Y_{i}^{*(2)} \quad \text { if } \quad Y_{i}^{*(1)}>0 \\
Y_{i}=0 \quad \text { if } \quad Y_{i}^{*(1)} \leq 0 .
\end{gathered}
$$

The covariate sets $\boldsymbol{X}_{1}$ and $\boldsymbol{X}_{2}$ may or may not be different subsets of $\boldsymbol{X}$. This type of model was introduced by Cragg (1971) as a more flexible alternative to the Tobit model. 
Sometimes called hurdle models, they allow the two outcomes to be determined by separate processes. In the health economics literature (see Jones 1989), $Y_{i}^{*(1)}$ is called the participation equation and $Y_{i}=I\left[Y_{i}^{*(1)}>0\right] \times Y_{i}^{*(2)}$ is the observed consumption (or award in the legal context), where $I[A]=1$ if the event $A$ occurs and is zero otherwise.

There are two main ways in the literature to interpret the two-part model. The first is to claim that it is not the unconditional, but the conditional expectation of $Y$ that is of interest to us. This approach is taken by Duan et al. (1983, 1984a, 1984b). The other approach is to stress the behavioral structure of the model (Maddala 1985), to which the selection process is central. In this case, selection and two-part models estimate the same behavioral relation. However, the two-part model makes an implicit distributional assumption for the unconditional distribution, which will be a mixing distribution, also depending on the distribution driving the selection mechanism.

Notice that the selection equation is the same for both the selection model and the two-part model; however, the conditional expectation, $E[Y \mid Y>0, \boldsymbol{X}]=\boldsymbol{\beta}^{T} \boldsymbol{X}$, does not involve the Mills ratio as in Equation (6). Also note that if $\mathrm{e}=0$, the selection and two-part models are equivalent. However, recall that the two-part model is modeling actual, not latent, outcomes. In the two part-model, the unconditional mean is $E[Y \mid \boldsymbol{X}]=\boldsymbol{\beta}^{T} \boldsymbol{X}_{2} \Phi\left(\boldsymbol{\alpha}^{T} \boldsymbol{X}_{1}\right)$.

As with the Tobit and selection models, the development of the selection model depends on the normality assumption, which is not appropriate for skewed award data. In the case of models in logs rather than levels, $E[Y \mid \boldsymbol{X}]=\exp \left(\boldsymbol{\beta}^{T} \boldsymbol{X}_{2}+\sigma^{2} / 2\right) \Phi\left(\boldsymbol{\alpha}^{T} \boldsymbol{X}_{1}\right)$.

\section{A Multilevel Two-Part Model}

Multilevel data structures consist of data measured at multiple levels. For example, one may have awards collected in distinct clusters (case type, locale, time). Data structured in this way are implicitly "hierarchical" insofar as there is a clear nesting of "lower-level" units within "higher-level" units. The natural hierarchy of this kind of data structure is why models considered in this subsection are sometimes called hierarchical models. Multilevel data structures need not be hierarchical (Gelman \& Hill 2007), however.

In the context of skewed punitive award data, assume that the award data are collected for $M$ clusters (e.g., case type, locale, time). For $i=, \ldots, 1, M$, and $j=1, n_{i}$, let $Z_{i j}$ denote the observed punitive damage award for trial $j$ within the $i$ th cluster, $\boldsymbol{X}_{i j}$ represent a vector of trial-specific characteristics, and $W_{i}$ be a vector of cluster (case type) specific characteristics. With inflated zero values, the observed awards are assumed to represent realizations of random variables whose probability distributions can be described by a mixture of a point mass at zero and a continuous distribution. Since the nonzero award data are always positive and heavily skewed to the right, they are modeled with a lognormal distribution. That is, $Z_{i j}=I\left(Y_{i j}^{*(1)}>0\right) \times \exp \left(Y_{i}^{*(2)}\right)$, where $Y_{i j}^{*(1)}$ and $Y_{i j}^{*(2)}$ represent two correlated latent random variables. Intuitively, $Y_{i j}^{*(1)}$ regulates when a zero award occurs and $Y_{i j}^{*(2)}$ is the natural logarithm of nonzero punitive damage awards.

A limitation of the two-part model described in the previous section is that it does not explicitly model correlated errors between the two parts, and any omitted variable introduces correlation. Zhang et al. (2006) proposed a two-part structure to model the 
dependence structure and hierarchical nature of the distributions of the two latent random variables $Y_{i j}^{(1)}$ and $Y_{i j}^{(2)}$. Specifically:

$$
\begin{array}{ll}
Y_{i j}^{*(1)}=\alpha_{0}+b_{i}^{(1)}+\alpha_{(1)}^{\mathrm{T}} X_{1 \mathrm{ij}}+\varepsilon_{1 \mathrm{ij}}, & \varepsilon_{1 \mathrm{ij}} \sim \mathrm{N}(0,1), \\
Y_{i j}^{*(2)}=\beta_{0}+b_{i}^{(2)}+\beta_{(1)}^{T} X_{2 i j}+\varepsilon_{2 i j}, & \varepsilon_{2 i j} \sim N\left(0, \sigma_{2}^{2}\right) .
\end{array}
$$

In the model above, the covariates $\boldsymbol{X}_{1 i j}$ and $\boldsymbol{X}_{2 i j}$ can be different subsets of $\boldsymbol{X}_{i j}$, representing the observed characteristics of trial $j$ within cluster type $i$. The $\varepsilon_{1 i j}$ and $\varepsilon_{2 i j}$ are assumed to be independent, and the variance of $\varepsilon_{1 j i}$ is set to 1 for identifiability. Our assumptions imply the conditional independence of $Y_{i j}^{*(1)}$ and $Y_{i j}^{*(2)}$ given $b_{i}^{()}$. The random effects $b_{i}^{(1)}$ and $b_{i}^{(2)}$ regulate the zero award and the logarithm of a nonzero award, respectively. One can think of $b_{i}^{(1)}$ as representing the $i$ th cluster type's tendency to award punitive damages at a trial (or, in the context of assessing compensatory damages, to find for plaintiff at trial) and $b_{i}^{(2)}$ as representing the $i$ th cluster's inclination to award high punitive damages (or to award compensatory damages). Treating $b_{i}^{(1)}$ and $b_{i}^{(2)}$ as having some probability distribution is what Gelman and Hill (2007) call a "soft constraint" variability; the mean effect is estimated, but is assumed to have some random variability around it. This variability is attributable to unmeasured factors.

The latent variables $Y_{i j}^{(1)}$ and $Y_{i j}^{(2)}$ are linked together by the correlated random effects $b_{i}^{(1)}$ and $b_{i}^{(2)}$, specifically:

$$
\left(\begin{array}{c}
b_{i}^{(1)} \\
b_{i}^{(2)}
\end{array}\right) \sim N\left(\left(\begin{array}{c}
\boldsymbol{\alpha}_{(2)}^{\mathrm{T}} \boldsymbol{W}_{1 \mathrm{i}} \\
\boldsymbol{\beta}_{(2)}^{\mathrm{T}} \boldsymbol{W}_{2 \mathrm{i}}
\end{array}\right), V\right),
$$

where $\boldsymbol{W}_{1 i}$ and $\boldsymbol{W}_{2 i}$ are the case-type-level characteristics; $\boldsymbol{V}_{2 \times 2}$ is assumed to be positive definite with the off-diagonal being allowed to be nonzero. The normality assumption on $b_{i}^{(1)}$ and $b_{i}^{(2)}$ is standard in random effects modeling (Gelman \& Hill 2007).

This two-part hierarchical model is composed of a hierarchical probit model and a hierarchical linear regression model. It is similar to that obtained by Olsen and Schafer (2001), who used a logit model for the binary part and considered the case where longitudinal observations were available on the same subject. The Appendix gives $R$ and OpenBugs code useful for fitting the two-part hierarchical model.

\section{Model Selection}

In choosing between the models one has to address the conceptual issue of what one is trying to model. The choice between the Tobit, selection, and two-part models revolves around whether we wish to model censored, latent, or observed outcomes (Dow \& Norton 2003; Puhani 2000). In the context of damage awards with observed zero awards, there is no censoring or latent structure. One is modeling actual fully observed awards, in which case the two-part model is more appropriate. Given that there is no censoring for the observed trial outcome data, the Tobit model should not be applied for award data.

In fully observed outcomes, zero values for damages indicate that zero dollars were awarded. In contrast, a latent outcome is a latent variable that is only partially observed. The observed zeros do not necessarily represent zero values in the latent outcome setting. If the zero damages are true zeros, there is no selection problem to address and no latent 
outcomes. Selection models can be used to estimate actual outcomes; however, they require extra calculations beyond what is reported in statistical packages. In Heckman's original applications, the focus was on the effect of education on wages. In the selection setting, one only has access to wage data for those who work and does not observe the wage for people who do not work, who will likely be those people only able to achieve a relatively low wage given their education. Since people who choose to work are selected nonrandomly from the population, estimating the determinants of wages from the subpopulation who choose to work introduces bias. In this setting, one may be interested in modeling the potential wages an individual could earn if he or she chooses to work. In this way one can then estimate the effect of a covariate such as education on both the fully observed and potential workers (Dow \& Norton 2003). In the context of damages with observed zero awards, there is no latent positive expected award that might have been observed.

Using maximum-likelihood estimation for fitting selection models can lead to numerical problems since the likelihood is not necessarily globally concave in $\mathrm{e}$. Therefore, there may be convergence issues since the maximization algorithm may not find the global maximum. An alternative to maximum-likelihood estimation is a two-step estimation method. In the first step, the selection equation is estimated using a probit and the inverse Mills ratio is then estimated for each case. The second step is an ordinary least squares regression with $\boldsymbol{X}$ and the inverse Mills ratio included as regressors. We will see in the examples below that the two-step estimation method can be problematic. Bushway et al. (2007) give a nice discussion of the issues related to two-step estimation for selection models in the context of criminological research.

Another issue in the choice between the selection and two-part models is that $\boldsymbol{X}_{\mathbf{1}}$ and $\boldsymbol{X}_{2}$ often have a large set of covariates in common and perhaps are even identical. The exclusion restrictions in the selection model are rarely if ever valid in trial outcome models. There are no exclusion restrictions if no variables that are in $\boldsymbol{X}_{2}$ are excluded from $\boldsymbol{X}_{1}$. Collinearity problems are inevitable since the Mills ratio is approximately linear over a wide range of its argument. The multicollinearity issue for the selection models has been investigated in some detail by Leung and Yu (1996) and Puhani (2000). They show, via some convincing simulation evidence, that the collinearity between the regressors in $X_{1}$ and the inverse Mills ratio (as a function of $\boldsymbol{X}_{2}$ ) is critical in terms of choosing between the sample selection and two-part models. If the condition number exceeds 20 , then the two-part model is more robust and should be used. A number of methods for detecting multicollinearity are outlined in Anderson and Wells (2008). The usual rule of thumb in practice is that a variance inflation factor (VIF) $\geq 4$ suggests that collinearity is a problem; some authors use the more lenient cutoff of VIF $\geq 5$. There are no identification issues for the two-part model as in the selection model; consequently, there is no multicollinearity issue as in the selection model.

\section{Data Analysis and Results}

We apply the two-part hierarchical model and relevant comparison models, including Tobit and selection models, to two data sets. The first consists of awards in 1980s and 1990s sexual 
harassment cases that led to reported opinions, the data used by Sharkey (2006), described below. The second consists of awards in 2005 in state court trials terminated in 46 large U.S. counties. The data come from the Civil Justice Survey of State Courts, a National Center for State Courts-Bureau of Justice Statistics project.

\section{A. The Data}

\section{The Sharkey Sexual Harassment Data}

Sharkey (2006) augmented a Sunstein and Shih (2004) data set that consisted of 70 reported cases, decided from 1983 to 1997 . Of the 70 cases, 56 included a positive noneconomic compensatory damages amount, and 40 included a positive punitive damages amount. The cases are listed in Sunstein and Shih (2004). Sunstein and Shih claim that their sample included all reported cases (from 1982 until February 1998) in which juries awarded damages in sexual harassment cases. Sunstein and Shih limited their sample to: (1) cases between plaintiff employee(s) and defendant employer(s)/supervisors/coemployees (i.e., excluding cases brought by the EEOC on behalf of employees); (2) cases raising at least one claim of sexual harassment under either Title VII of the Civil Rights Act of 1964 or state civil rights laws; (3) cases involving trial by jury; and (4) cases in which the jury awarded some positive amount of damages on the basis of sexual harassment. Professor Sharkey generously furnished us an expanded data set from February 1998 (where the Sunstein and Shih ends) to May 2004.

The total sample size, including all reported plaintiff win cases from 1983 until 2004, consists of 232 cases. Of these, 203 had nonzero, nonmissing information about the compensatory award. Of the 232 cases, 146 had a nonzero punitive award. The cases with compensatory award information included 116 with information about punitive awards. Table 1 reports descriptive statistics for the variables used in our models.

The histogram in Figure 1 shows the distribution of the punitive awards, which include 86 cases with no punitive award, and uses a logarithimic transformaton for nonzero awards. The Sharkey data are precisely the type of data discussed above, that is, logarithmically transformed trial outcomes with a large proportion of zeros. The second graph in Figure 1 is a scatterplot of the punitive and compensatory awards, both logarithmically transformed, for the 115 cases with positive punitive and compensatory awards and a compensatory award of at least $\$ 100$. The correlation coefficient for the two awards is 0.31 , significant at $p<0.001$.

Sharkey (2006) included factors that might be associated with the nature and severity of harassment: propositions by the harasser; visual display of pornography or body parts; coerced sex; verbal abuse; any unwanted physical contact; other evidence of a pattern of behavior; and whether plaintiff is alleged to have participated in the harassment, including situations where the plaintiff has engaged in consensual sexual relations with the defendant. Sharkey also coded the number of defendants according to how many defendants were ordered to pay damages to the plaintiff, variables pertaining to the damages limitations of Title VII (whether the harassing activity took place on or after November 21, 1991, the relevant effective date of the Civil Rights Act of 1991), and whether the outcome was reversed on appeal. 
Table 1: Descriptive Statistics of Variables in Regression Models of Jury Punitive Damages Awards, Sexual Harassment Cases, 1983-2004

\begin{tabular}{lrrrrr}
\hline Variable & $\mathrm{N}$ & Mean & SD & Minimum & Maximum \\
\hline Compensatory award & 208 & $270,824.5$ & $462,125.4$ & 0 & $3,120,000$ \\
Punitive award & 207 & $760,993.0$ & $4,444,685.0$ & 0 & $6.15 \mathrm{e}+07$ \\
Behavior pattern involving others & 191 & 0.30 & 0.46 & 0 & 1 \\
Behavior pattern involving plaintiff & 193 & 0.68 & 0.47 & 0 & 1 \\
Coerced sex & 189 & 0.05 & 0.22 & 0 & 1 \\
Employment effects & 216 & 0.69 & 0.47 & 0 & 1 \\
Multiple harassers & 193 & 0.26 & 0.44 & 0 & 1 \\
Physical contact & 190 & 0.68 & 0.47 & 0 & 1 \\
Plaintiff participated & 191 & 0.05 & 0.21 & 0 & 1 \\
Proposition & 191 & 0.47 & 0.50 & 0 & 1 \\
Quid pro quo & 221 & 0.16 & 0.37 & 0 & 1 \\
Reversed & 232 & 0.27 & 0.45 & 0 & 1 \\
State ranking index & 230 & 9.97 & 7.35 & 1 & 23 \\
Verbal abuse & 190 & 0.84 & 0.37 & 0 & 1 \\
Visual (picture or gesture) & 190 & 0.17 & 0.38 & 0 & 1 \\
Year & 232 & $1,998.0$ & 4.13 & 1983 & 2004 \\
1991 Act & 232 & 0.78 & 0.42 & 0 & 1 \\
\hline Note The & & 0.9 &
\end{tabular}

NoTE: The sample consists of sexual harassment cases, available on Westlaw and decided from 1983 through May 2004, in which juries awarded damages to plaintiffs.

Sharkey also coded variables for quid pro quo harassment and effect on employment. Employment effects include three subcategories: fired, quit, and other negative effects short of firing (including unwanted transfers and retaliatory hostility from co-workers). One would expect much overlap between the variables for quid pro quo and employment effects. Both the Sharkey and Sunstein and Shih studies attempt to control for time differences by including indicator variables for the trial year. The trial year is either reported in the decision or, if not, they coded the trial year as one year prior to the reported appellate decision (or else the same year as a trial court opinion).

Sunstein and Shih had difficulty controlling for state effects given their small sample. Because their data sets were too small to use state dummy variables, both Sunstein and Shih and Sharkey included a proxy for state fixed effects, a ranking of state product liability punitive damages awards, derived from data on product liability cases. The ranking variable is based on the percentage of product liability cases in which punitive damages are awarded (Sharkey 2006:21).

Sharkey's empirical study used standard ordinary least squares regression models with a logged dependent variable since the distribution of the nonlogged variables for damages was right-skewed. Sunstein and Shih ran Tobit models to take into account zero values (which are excluded by a logged OLS dependent variable).

\section{The Civil Justice Survey Data}

The Civil Justice Survey data for 2005 included 46 of the 75 most populous counties and 110 other counties to represent the 3,066 smaller counties not included in the country's 75 
Figure 1: The histogram shows the distribution of punitive awards in 202 sexual harassment cases, available on Westlaw and decided from 1983 through May 2004, in which juries awarded compensatory damages to plaintiffs. The scatterplot shows the relation between punitive and compensatory awards in 115 cases with both types of awards. All damages amounts are adjusted for inflation, in 2004 dollars.

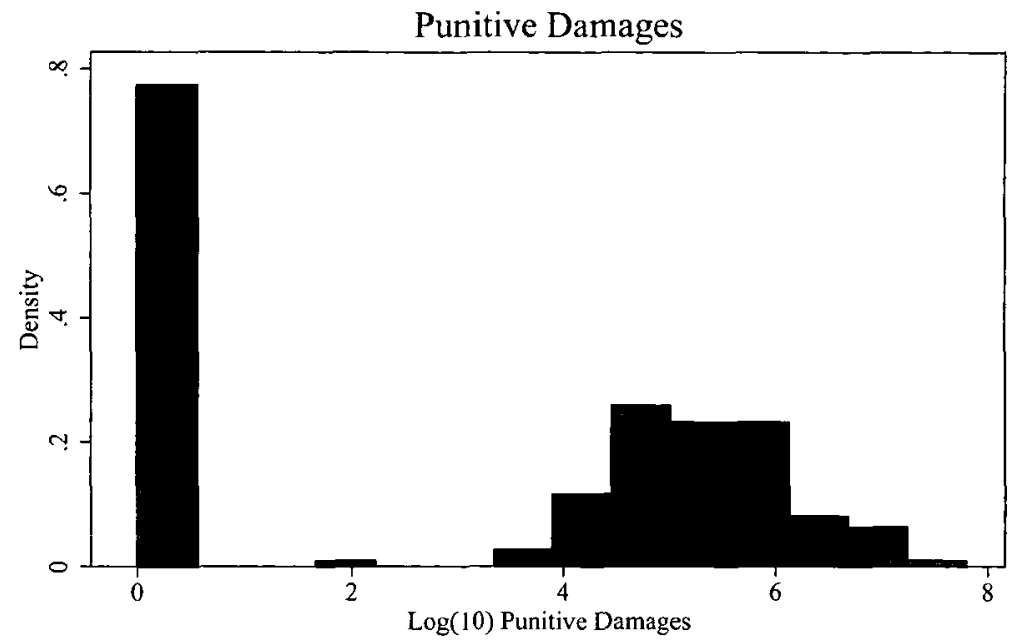

202 sexual harassment cases with compenastory damages $>0$ and punitive award information, 1983 to May 2004

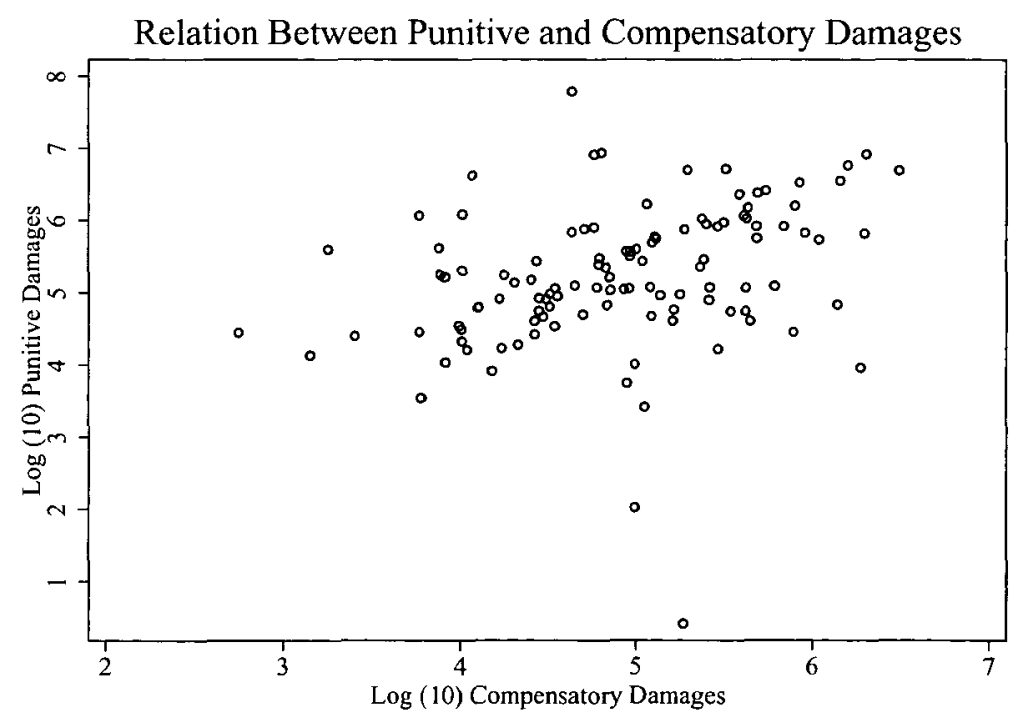


Table 2: Descriptive Statistics of Variables in Regression Models of Punitive Damages Awards, State Court Trials, 2005

\begin{tabular}{lrrrrr}
\hline Variable & $\mathrm{N}$ & Mean & SD & Minimum & Maximum \\
\hline Compensatory award & 342 & $1,573,830$ & $7,362,256$ & 0 & $80,100,000$ \\
Punitive award & 130 & $2,814,046$ & $11,300,000$ & 0 & $115,000,000$ \\
Motor vehicle tort & 353 & 0.10 & 0.30 & 0 & 1 \\
Intentional tort & 353 & 0.10 & 0.30 & 0 & 1 \\
Fraud & 353 & 0.20 & 0.40 & 0 & 1 \\
Buyer plaintiff (contract) & 353 & 0.10 & 0.30 & 0 & 1 \\
Employment-other & 353 & 0.06 & 0.24 & 0 & 1 \\
Other & 353 & 0.44 & 0.50 & 0 & 1 \\
\hline
\end{tabular}

Note: The sample consists of state court trials in large counties, concluded in 2005 , in which punitive damages were sought.

largest counties (Bureau of Justice Statistics 2008). The data included all trials completed in the studied counties in 2005 and included a variable that reported whether punitive damages had been sought in each case. The 2005 data include 8,872 trials of an estimated total of 27,128 in state courts in the United States in 2005 , or 32.7 percent. Based on the sample design, the trials from the 46 counties are estimated to represent 10,813 general bench and civil trials disposed of in the nation's 75 most populous counties. Evidence of heterogeneity in award patterns exists as between the large and small counties (Eisenberg et al. 2010). We limit our analysis here to the small fraction of cases, 342 trials in the large counties, in which punitive damages were sought and there was a nonzero compensatory award. Information about whether punitive damages were sought was not available in the Sharkey data.

Of these 342 trials seeking punitive damages, 130 (37.4 percent) resulted in a punitive award. The Civil Justice Survey data do not have the richer detail about cases contained in the opinions in the Sharkey data. They do include information about the kind of case or the locale of the case. Prior models using these data include selection models of whether punitive damages were awarded (Eisenberg et al. 2010), but not of the amount of a punitive award, conditional on a punitive award being sought. Table 2 reports descriptive statistics for the variables used in our models.

The histogram in Figure 2 shows the distribution of the punitive awards, which include 208 cases with no punitive award, and uses a logarithmic transformation for nonzero awards. Like the Sharkey data, the data have a large proportion of zeros. The second graph in Figure 2 is a scatterplot of the punitive and compensatory awards, both logarithmically transformed, for the 130 cases with positive punitive and compensatory awards. The correlation coefficient for the two awards is 0.80 , significant at $p<0.001$. Note that the Civil Justice Survey data, not biased by the filtering leading to available opinions in the Sharkey data, show a much higher fraction of zero punitive awards and a much stronger correlation between the punitive and compensatory awards.

\section{B. Model Estimation}

The Tobit and selection models were performed using Stata version 13 (StataCorp) with robust standard errors clustered by time in the Sharkey data and by state in the Civil Justice 
Figure 2: The histogram shows the distribution of punitive awards in 342 state court trial outcomes from the 2005 Civil Justice Survey in which compensatory damages were awarded to plaintiffs. The scatterplot shows the relation between punitive and compensatory awards in 135 cases with both types of awards.

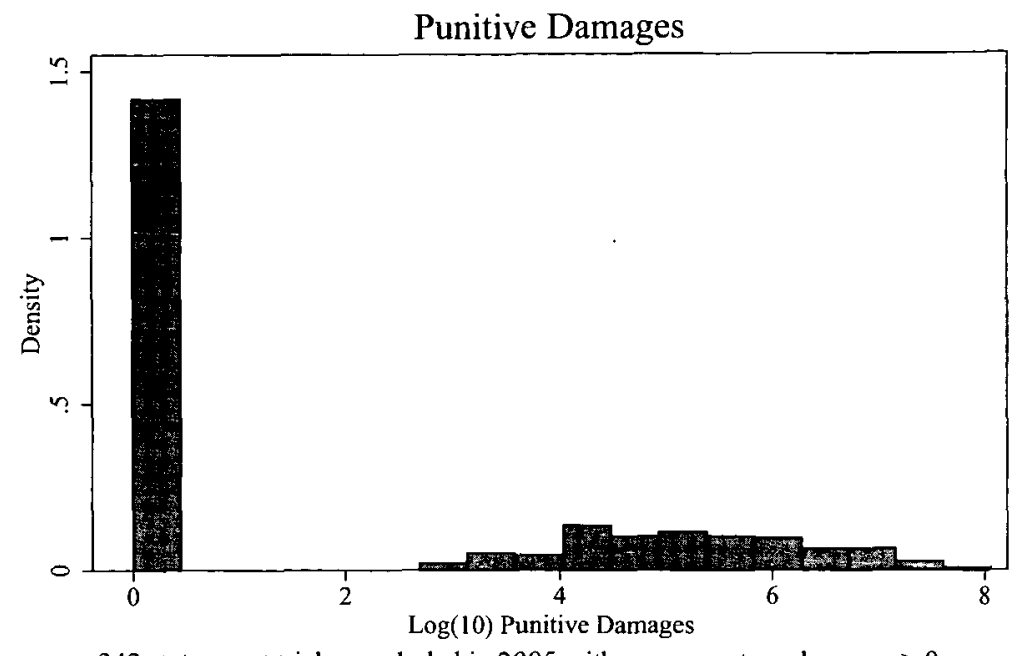

342 state court trials concluded in 2005 with compenastory damages $>0$ and punitive award information, 1983 to May 2004

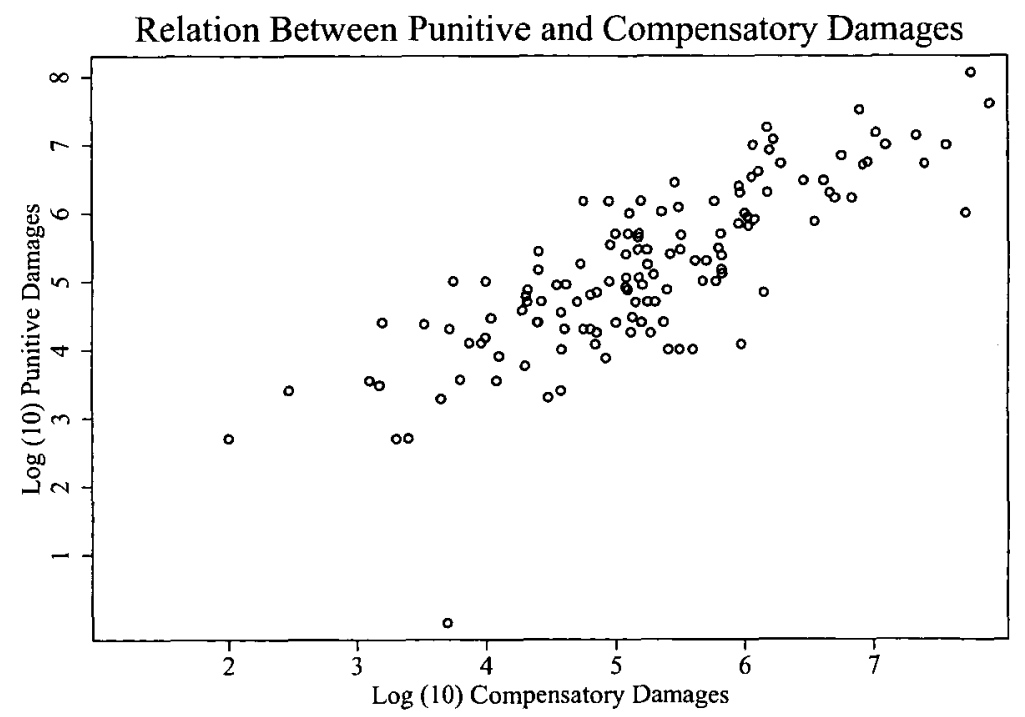


Survey data to correct the variance estimates due to the presence of conditional dependence from the multiple cases with the cluster. In the case the data are not clustered, the two-part model can be fit using one regression at a time because of the separability of the likelihood function. In the case of clustered data (time in the Sharkey data and state in the Civil Justice Survey data), we use the Bayesian approach outlined in Zhang et al. (2006) to fit the two-part model with a cluster-specific random intercept. The Bayesian approach to two-part modeling has certain advantages over non-Bayesian approaches. In principle, all prior distributions we use are specified to be as noninformative as possible. A normal distribution, $N\left(0,10^{6}\right)$, was chosen for the regression model parameters, that is, $\alpha s$ and $\beta s$, and an inverse Gamma $\left(1,10^{-3}\right)$ prior was chosen for the variance parameter $\sigma_{\ell}^{2}$; see Speckman and Sun (2003) for details regarding the propriety of the corresponding posteriors.

Selecting a prior for the covariance matrix $V$ turned out to be a more challenging problem. The conjugate prior, inverse Wishart (1928), is commonly used in practice. However, the inverse Wishart prior has a tendency to force the eigenvalues of the covariance matrix apart (Yang \& Berger 1994). The results of Yang and Berger suggest that the reference prior should outperform Jeffreys (1946) prior, to which the inverse Wishart prior is approximately equal, due to the tendency of the latter to spread out the eigenvalues. Because of the hidden undesirable features of the inverse Wishart priors, we experimented with various other priors (Daniels \& Pourahmadi 2002).

The reference prior of Yang and Berger (1994), being improper, ${ }^{1}$ avoids the problem of placing significant probability mass on covariance matrices with diffuse eigenstructures. However, WinBUGS (Spiegelhalter et al. 2000) requires the use of proper prior distributions. We will use an approximation of the Yang and Berger reference prior. The covariance matrix can be expressed as:

$$
V=\left(\begin{array}{cc}
\max \left(d_{1}, d_{2}\right)-\delta \gamma^{2} & -\delta \gamma \sqrt{1-\gamma^{2}} \\
-\delta \gamma \sqrt{1-\gamma^{2}} & \min \left(d_{1}, d_{2}\right)+\delta \gamma^{2}
\end{array}\right),
$$

where both $d_{1}$ and $d_{2}$ are positive, $\delta=\left|d_{1}-d_{2}\right|$, and $\gamma \in(-1,1)$. Our approximate reference prior is obtained by assuming $\gamma$ Uniform $(-1,1)$ and that $d_{1}$ and $d_{2}$ are independent Gamma $(0.5,100)$ random variables. This prior, "informative" in the sense that the prior means and variances of the components of $V$ are all finite, is used in the data analysis of the next subsection.

The posterior distributions of $\boldsymbol{\alpha}, \boldsymbol{\beta}, \sigma_{\varepsilon}^{2}, \boldsymbol{V}$, and $\left\{\boldsymbol{b}_{i}: i=1, \ldots, M\right.$ given the observed data are very complicated and neither amenable to analytical calculation nor direct Monte Carlo sampling so Markov chain Monte Carlo (MCMC) methods are used to approximate the posterior distributions. Initial values were set to 1,000 for variance and 0 for nonvariance parameters. Priors are specified according to the previous discussion. Convergence of the MCMC sampling scheme was assessed using both empirical (Gelfand \& Smith

\footnotetext{
${ }^{1}$ If the integral of the prior values is infinite but still yields sensible answers for the posterior probabilities, the prior is called an "improper" prior.
} 
1990) and test-based approaches (Cowles \& Carlin 1996). Results from convergence diagnostics indicated that it was sufficient to burn in the first 10,000 samples and take the following 10,000 samples for inference.

\section{Results}

Tables 3 and 4 report results of the models discussed for the sex discrimination data and the Civil Justice Survey data, respectively. The tables illustrate important methodological issues for the various models.

\section{Results for the Sharkey Sexual Harassment Data}

In Table 3, the Tobit, OLS (fe), and selection regressions control for fixed trial year effects by including indicator trial year variables. None of the coefficients on the trial year dummy variables was significant at $p \leq 0.05$. The two-part model uses a trial year random effect as the cluster variable, as did Sharkey in her analysis of the data. The Tobit model in Column 1 includes cases with a punitive award of zero. The OLS regressions in Columns 3 and 4 are limited to cases with nonzero punitive awards. The two-part and selection models jointly estimate the probability of a positive award and the level of the award. The mean award amount models in Columns 3, 4, 5, 6, and 8 use logged values for punitive damages (dependent variable) and compensatory damages (independent variable). The existence of award results shown in Column 7 is the same for both Heckman models so we report the Heckman existence equation results only once.

Sunstein and Shih ran Tobit models to account for zero values and did not find a positive relationship between the size of compensatory and punitive damages. However, the histogram in Figure 1 indicates that the Tobit model in the untransformed award scale does not provide a good fit for the data. Using an OLS methodology for log transformed positive awards, Sharkey (2006) finds a consistently (strongly statistically significant) positive relationship between the size of compensatory and punitive damages. But the OLS model reported excluded cases with no punitive damages award. The Heckman models and the two-part model provide some reconciliation of the Tobit and OLS approaches. They allow inclusion in the model of the cases with zero punitive awards but do not questionably treat the zero awards as censored.

With respect to the relation between compensatory awards and the amounts of punitive awards in cases with punitive awards, the second Heckman model (Column 9 of Table 3) and the two-part model yield results similar to the OLS model. These models suggest a positive association between compensatory and punitive awards, while also accounting for zero-award cases, which the OLS model does not include. Note that the marginal significance in the OLS model differs from Sharkey's larger and more significant coefficient $(\beta=0.297 ; p<0.001)$. The fixed effect year variables used here differ from the clustering on year reported by Sharkey. The multiple dummy variables resulted in some evidence of multicollinearity, with an average VIF of 6.66 in the OLS model. Two outlying observations also affected the model; with their exclusion, even a model with year fixed effects yields significant results, as does quantile regression even with the outlying observations. The utterly insignificant relation between the compensatory and punitive awards in 


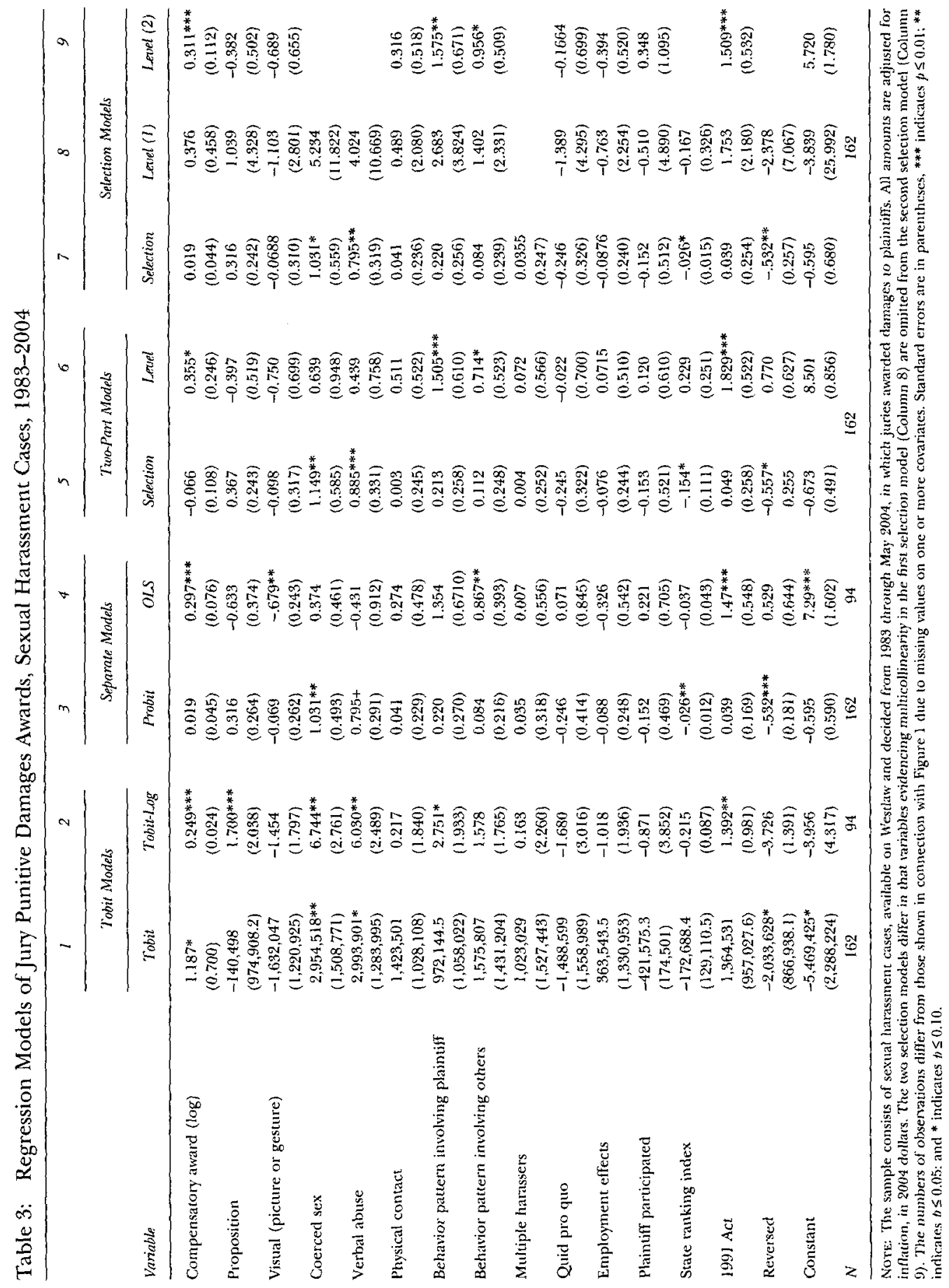




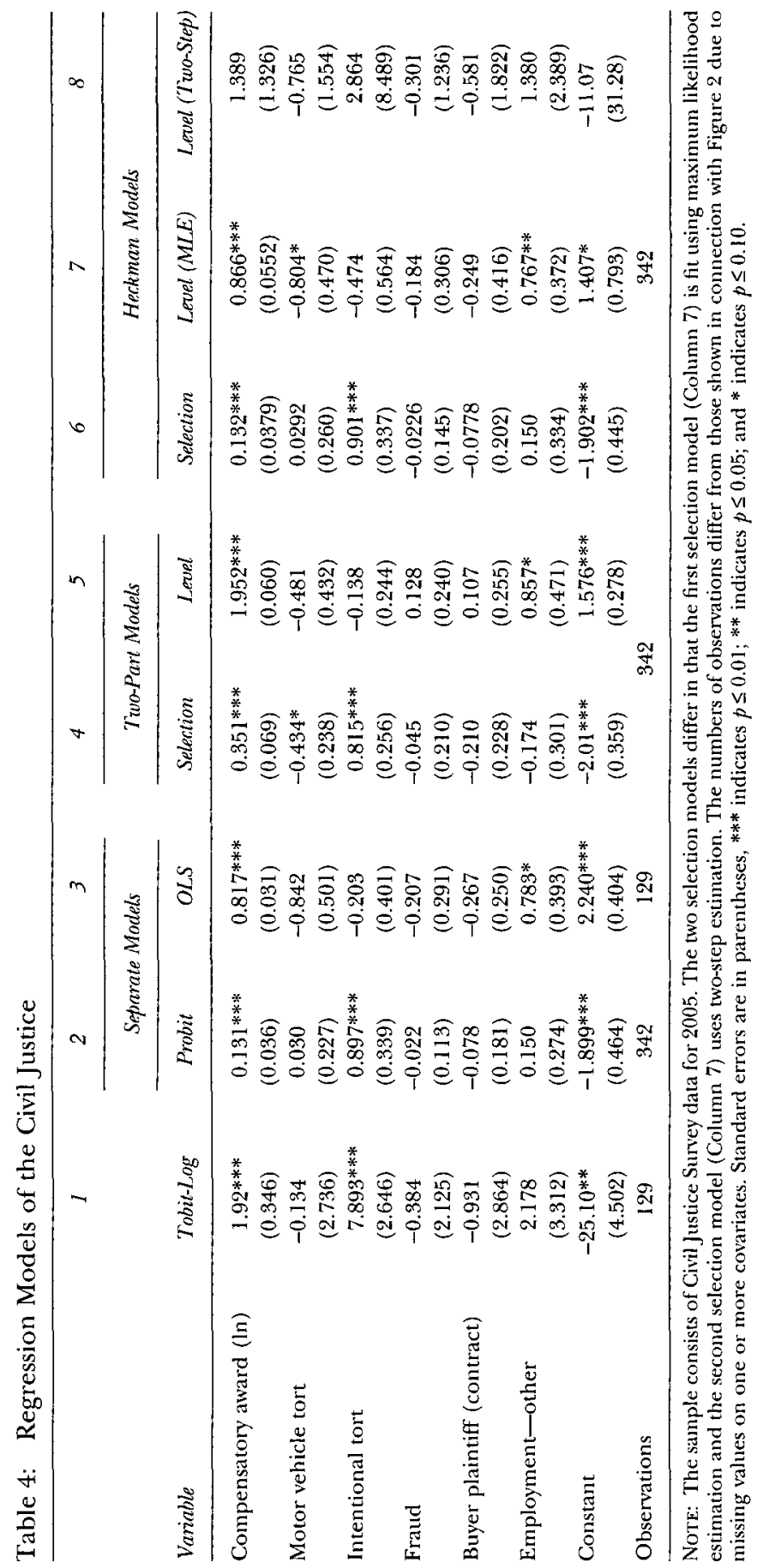


the Tobit model, as also reported in models used by Sunstein and Shih and Sharkey, is due to the dominance of zero awards in the Tobit model.

Two Heckman models are reported to illustrate the importance of collinearity for such models when estimated using the Heckman two-step method (the method used in the Heckman models in Table 3). In the case of the Sharkey data, only the two-step procedure was available because a maximum-likelihood model with fixed effects for years failed to converge. The first selection model is just identified via an exclusion restriction. However, as pointed out above, the selection and mean models may have a large set of common covariates (and perhaps are even identical). Collinearity problems are inevitable since the Mills ratio is approximately linear over a wide range of its argument. Leung and Yu (1996) suggest if variance inflation factors are too large, the two-part model is more robust and should be used. Computing the VIF in the first selection model (Column 8 of Table 3), we find VIF (Mills RATIO) $=59.23$, VIF (VERBal ABUSE) $=18.88$, VIF $($ COERCED SEX $)=18.38$, $\operatorname{VIF}($ REVERSED $)=16.50, \operatorname{VIF}($ STATE RANKING $)=9.75$, and VIF $($ PROPOSITION $)=8.88$. Hence the nonsignificance of many coefficients in the first selection model is a consequence of the collinearity problem. Removing the VERBAL ABUSE, COERCED SEX, REVERSED, and STATE RANKING explanatory variables from the first selection model we see that the results of the second selection model (Column 5) are much more similar to the two-part model. In the second selection model, the largest variance inflation factor is now VIF(MILLS RATIO) $=2.50$; consequently, collinearity is no longer an issue. These problems lead to the two-step procedure being essentially useful in modeling the Sharkey data, and yield results that are consistent with all other models. There are no identification restrictions for the two-part model as in the selection model; consequently, there is no multicollinearity issue as in the selection model.

The useful Heckman model (Column 8 of Table 3) and the two-part model each show a statistically significant, positive relation between the CiviL RIGHTs Act of 1991 variable and punitive damages award amounts. This is to be expected because that Act authorized punitive damage awards in some new categories of Title VII cases. The Tobit model in levels has a insignificant coefficient for this variable, suggesting its inconsistency with the models that are better suited to the data.

In general, the Tobit model is similar in result to the probit models and the existence portions of the Heckman and two-part models. They each yield small, insignificant comPENSATORY AWARD coefficients. They each yield statistically significant or near-significant COERCED SEX, REVERSED, and VERBAL ABUSE coefficients. The significance of the COERCED SEX, VERBAL ABUSE, and REVERSED variables in the Tobit model is clearly due to the confounding of the significance of those variables in the probability of a punitive award. However, the Tobit model is inadequate in capturing the relation between any variables and the level of a nonzero award; the dominance of zero values in the dependent variable drives the results. Models that account for the existence of nonzero awards and their level are superior.

Sunstein and Shih are quite emphatic about the robustness of their Tobit regression results: "No matter what method, regression, or data set is used, higher compensatory awards do not produce higher punitive damages." The Sunstein and Shih results seem to depend on the extreme influence of a handful of observations and are confounded by the 
variables that significantly predict nonzero awards. In terms of the $\log$ transformed models, a statistically significant relation between punitive $(\log )$ and compensatory $(\log )$ awards is evident. This relation is consistent with the mass of punitive damages studies (e.g., Eisenberg et al. 2006).

Our goal in analyzing the Sharkey data is not to produce the best model. In part, we sought to maintain continuity with the Sunstein and Shih and Sharkey analyses. Further refinement of the models might include accounting for correlations among the group of explanatory variables. For example, about 60 percent of the cases jointly had, or did not have, both a quid pro quo and a proposition in their facts. But these subtleties have little impact on the core research question of whether punitive and compensatory damages are significantly associated, as suggested by Figure 1.

\section{Results for the Civil Justice Survey Data}

Table 4 reports results for punitive damages awards in the Civil Justice Survey data for 2005 . The models for existence of punitive damages for the Civil Justice Survey data show a significant relation between the amount of the compensatory award and the existence of a punitive award. None of the existence models for the Sharkey data show that relation. This may be because the Civil Justice Survey data have information about all trials in which punitive damages were requested. The Sharkey data have been filtered by decisions to report results in opinions and decision to appeal, which may yield less useful estimates of this relation.

As with the Sharkey data example, the two Heckman models are reported to illustrate the importance of collinearity using the Heckman two-step method. In the case of the Civil Justice Survey data, Columns 7 and 8 of Table 4 give the maximum-likelihood estimates and two-step estimates, respectively. Computing the VIF for the two-step method (Column 8), we find the VIF (MILlS RATIO) $=142.34$, VIF (LOG COMPENSATORY DAMAGES) $=95.39$, and VIF $($ INTENTIONAL TORT $)=52.83$. Hence the nonsignificance of all the coefficients in the two-step selection model is likely a consequence of the collinearity problem. The maximumlikelihood estimates for the selection model (Column 7) are much more similar to the two-part model (Column 5).

All the models agree on the strong log punitive and log compensatory association. The maximum-likelihood estimates for the Heckman model (Column 7 of Table 4) and the two-part model (Column 5) agree on the significance and nonsignificance for EMPLOYMENT and intentional TORT, respectively, whereas the Tobit model flips the significance. The agreement between the two-part, maximum-likelihood selection, and the separate models in these data is likely because of lack of dependence between the selection and level error terms $(p=0.16$ for testing; $\mathrm{Q}=0$ in the selection model $)$.

\section{Discussion And Conclusion}

The two-part model is suitable for modeling data with many observed zero damage awards; however, use of the two-part model is not a substitute for careful thought about the nature 
of the data. When zeros are not actually observed, the two-part model is not applicable. For example, the two-part model suits modeling the compensatory or total damages award in cases in which victories for defendants can reasonably be regarded as awards of zero compensatory damages. Similarly, in cases in which plaintiffs win and properly seek punitive damages, models of punitive damages in cases won by plaintiffs may reasonably treat the cases without punitive damages as punitive awards of zero.

But in cases in which it is unknown whether plaintiffs sought punitive damages, the award of punitive damages often is not actually observed. The absence of a punitive award may not be an actual zero award but may merely reflect that punitive damages were not sought. Use of the two-part model, or other models of the existence of a punitive award, absent information about whether punitive damages were sought may be inappropriate. In the case of Title VII actions, where the vast majority of cases involve claims of intentional discrimination (Nielsen et al. 2010:192), it seems reasonable to assume that punitive damages were sought, but our numerical results are subject to that assumption. Evidence exists that punitive damages are sought less frequently than is widely believed (Eisenberg et al. 2010).

The models discussed in this article all involve important assumptions in addition to those about the observability of zero awards. The assumptions include the normality of random effects and error terms, the linear relationship between probit-probability and covariates for modeling the probability of having positive awards, and the linear relationship between log-award and covariates. We also evaluated the impact of our model assumptions in other ways. For example, separately fitting a generalized linear mixed model to the binary portion and a linear mixed model to the continuous part indicated that the corresponding estimates were quite close to the posterior means reported in Table 3 . We obtained similar Bayesian estimates using a logit rather than probit link. The use of various Gamma and inverse Gamma prior distributions for variance parameters are robust and have very little effect on the posteriors. We evaluated the sensitivity of the results for both "noninformative" and "informative" versions of our priors and the results were rather insensitive to the choice of prior family.

Although it has been known that Tobit models are questionable in the case of data containing many actually observed zeros, the use of Tobit models in that context remains common. The Tobit results reported here fail to capture important features of the data and completely miss the strong association between punitive and compensatory awards in cases with punitive awards. The two-part model presented here allows researchers who wish to model case outcome data or other social science data with many zeros to do so without having to rely inappropriately on Tobit models. A statistical contribution of this article is the introduction of the Bayesian version of a two-stage hierarchical model by Zhang et al. (2006) that is able to deal with the clustered and highly skewed nature of damage award data.

\section{REFERENCES}

Anderson, W., \& M. T. Wells (2008) "Numerical Analysis in Least Squares Regression with an Application to the Abortion-Crime Debate," $5 \mathrm{~J}$. of Empirical Legal Studies 647. 
Berger, J. O. (1985) Statistical Decision Theory and Bayesian Analysis. New York: Springer-Verlag.

Bureau of Justice Statistics (2008) Special Report: Civil Justice Survey of State Courts, 2005: Civil Bench and Jury Trials in State Courts, 2005. Washington, DC: Bureau of Justice Statistics.

Bushway, S., B. D. Johnson, \& L. A. Slocum (2007) "Is the Magic Still There? The Use of the Heckman Two-Step Correction for Selection Bias in Criminology," $23 \mathrm{~J}$. of Quantitative Criminology 151.

Cowles, M. K., \& B. P. Carlin (1996) "Markov Chain Monte Carlo Convergence Diagnostics: A Comparative Review," $91 \mathrm{~J}$. of the American Statistical Association 883.

Cragg, J. G. (1971) "Some Statistical Models for Limited Dependent Variables with Application to the Demand for Durable Goods," 39 Econometrica 829.

Daniels, M. J., \& M. Pourahmadi (2002) "Bayesian Analysis of Covariance Matrices and Dynamic Models for Longitudinal Data," 89 Biometrika 553.

De Ruijter, E., \& B. Braat (2008) "Co-Working Partners: The Influence of Legal Arrangements," 22 International J. of Law, Policy E the Family 421.

Dow, W., \& E. Norton (2003) "Choosing Between and Interpreting the Heckit and Two-Part Models for Corner Solutions," 4 Health Services $\mathcal{E}$ Outcomes Research Methodology 5.

Duan, N., W. G. Manning, C. N. Morris, \& J. P. Newhouse (1983) "A Comparison of Alternative Models for the Demand for Medical Care," 1(2) J. of Business E' Economic Statistics 115.

(1984a) "Choosing Between the Sample-Selection Model and the Multi-Part Model," 2(3) J. of Business \& Economic Statistics 283.

(1984b) "Comments on Selectivity Bias," 6 Advances in Health Economics $\mathcal{F}$ Health Services Research 19.

Eisenberg, T., P. L. Hannaford-Agor, M. Heise, N. LaFountain, G. T. Munsterman, B. Ostrom, \& M. T. Wells (2006) "Juries, Judges, and Punitive Damages: Empirical Analyses Using the Civil Justice Survey of State Courts 1992, 1996, and 2001 Data," 3 J. of Empirical Legal Studies 263.

Eisenberg, T., M. Heise, N. L. Waters, \& M. T. Wells (2010) "The Decision to Award Punitive Damages: An Empirical Study," 2 J. of Legal Analysis 577.

Eisenberg, T., \& M. T. Wells (2006) "Significant Association Between Punitive and Compensatory Damages in Blockbuster Cases: A Methodological Primer," $3 \mathrm{~J}$. of Empirical Legal Studies 175.

Fehr, E., \& Simon Gāchter (2000) "Cooperation and Punishment in Public Goods Experiments," 90 American Economic Rev. 980.

Gelfand, A. E., \& A. F. M. Smith (1990) "Sampling-Based Approaches to Calculating Marginal Densities," 85 J. of American Statistical Association 398.

Gelman, A., \& J. Hill (2007) Data Analysis Using Regression and Multilevel/Hierarchical Models. Cambridge: Cambridge Univ. Press.

Greene, W. (2008) Econometric Analysis, 6th ed. New York: Macmillan.

Heckman, J. (1979) "Sample Selection Bias as a Specification Error," 47 Econometrica 153.

Hersch, J., \& W. K. Viscusi (2004) "Punitive Damages: How Judges and Juries Perform," 33 J. of Legal Siudies 1.

Jeffreys, H. (1946) "An Invariant Form for the Prior Probability in Estimation Problems," 186(1007) Proceedings of the Royal Socieiy of London. Series A, Mathematical E Physical Sciences 453.

Jones, A. M. (1989) "A Double-Hurdle Model of Cigarette Consumption," 4(1) J. of Applied Econometrics 23.

Leung, S. F., \& S. Yu (1996) "On the Choice Between Sample Selection and Two-Part Models," 72 J. of Econometrics 197.

Maddala, G. S. (1985) "Further Comments on Selectivity Bias," 6 Advances in Heallh Economics $\mathcal{E}^{2}$ Heallh Services Research 25. (1992) Introduction to Econometrics, 2nd ed. New York: Macmillan.

Nielsen, L. B., R. L. Nelson, \& R. Lancaster (2010) "Individual Justice or Collective Legal Mobilization? Employment Discrimination Litigation in the Post Civil Rights United States," $7 \mathrm{~J}$. of Empirical Legal Studies 175.

Olsen, M., \& J. L. Schafer (2001) “A Two-Part Random-Effects Model for Semicontinuous Longitudinal Data," $96 \mathrm{~J}$. of the American Statistical Association 730. 
Puhani, P. (2000) "The Heckman Correction for Sample Selection and its Critique," 14(1) J. of Economic Surveys 53.

Sharkey, C. M. (2006) "Dissecting Damages: An Empirical Exploration of Sexual Harassment Awards," 3 J. of Empirical Legal Studies 1.

Speckman, P. L., \& D. Sun (2003) "Fully Bayesian Spline Smoothing and Intrinsic Autoregressive Priors," 90 Biometrika 289.

Spiegelhalter, D., A. Thomas, \& N. Best (2000) WinBUGS, Version 1.3 User Manual. MRC Biostatistics Unit.

Sunstein, C. R., \& J. Shih (2004) "Damages in Sexual Harassment Cases," in C. A. Mackinnon \& R. B. Siegel, eds., Directions in Sexual Harassment Law. New Haven, CT: Yale University Press.

Thompson, J. R., T. M. Palmer, \& S. Moreno (2006) "Bayesian Analysis in Stata Using WinBUGS," 6(4) Stata J. 530.

Tobin, J. (1958) "Estimation of Relationships for Limited Dependent Variables," 26 Econometrica 24.

Wishart, J. (1928) "The Generalised Product Moment Distribution in Samples from a Normal Multivariate Population," 20A(1-2) Biometrika 32.

Wooldridge, J. (2010) Econometric Analysis of Cross Section and Panel Data, 2d ed. Cambridge, MA: MIT Press.

Yang, R., \& J. O. Berger (1994) "Estimation of a Covariance Matrix Using the Reference Prior," 22 Annals of Statistics 1195.

Zhang, M., R. L. Strawderman, M. E. Cowen, \& M. T. Wells (2006) "Bayesian Inference for a Two-Part Hierarchical Model: An Application to Profiling Providers in Managed Health Care," $101 \mathrm{~J}$. of the American Statistical Association 934. 


\section{Appendix: Code for Givil Justice Survey Data- Two-PART MODELS}

To illustrate the methodology behind our Bayesian two-part models, the $R$ and OpenBUGS code are displayed in this section. Methods for Bayesian analysis in Stata using WinBUGS can be found in Thompson et al. (2006). For reference in the Civil Justice Survey data, parameters that begin with "alpha" are from the selection component and those that begin with "beta" are from the amount component. The variable numbering is as follows: $x 1$ refers to the natural logarithm of the compensatory award, $x 2$ is the motor vehicle tort dummy, $x 3$ is for intentional torts, $x 4$ represents fraud, $x 5$ represents "buyer plaintiff (contract)," and $x 6$ is "employment-other." Parameters denoted with 0 are constants. Below is the OpenBUGS code that can be used in a $R$ workspace environment:

\#N - total number of observations

$\# M-$ number of sites

\#load the data, resulting data frame is called pd_342

setwd ("...")

$\mathrm{y}<-$ pd_342\$y

$\mathrm{x} 1<-$ pd_342\$x1

$\mathrm{x} 2<-$ pd_342\$x2

$\mathrm{x} 3<-p d 342 \$ \mathrm{x} 3$

$\mathrm{x} 4<-p d 342 \$ \mathrm{x} 4$

ID<-pd_342\$id

x6<-pd_342\$ $\$ 6$

$\times 5<-p d 342 \$ \times 5$

$\mathrm{N}<-342$

$\mathrm{M}<-25$

pd342_data<-list ("M", "N", "ID", "y", "x1", "x2", "x3", "x4", "x5", "x6")

\# Initial Values

inits <- function ( ) \{list (alpha0 $=-0.5$, alpha1 $=0.2$, alpha2 $=-0.1$, alpha3 $=0$, alpha4 $=0$, alpha $5=0$, alpha $6=0.2$, beta $0=5$, beta $1=0.8$, beta $2=0.1$, beta $3=0$, beta $4=0$, beta $5=0$, beta $6=0, a=0, z 1=1, z 2=1$, taue $=1)$ \}

\# Parameters of Interest

parameters <- c("alpha0", "alphal", "alpha2", "alpha3", "alpha4", "alpha5", "alpha6", "beta0", "beta1", "beta2", "beta3", "beta4", "beta5", "beta6", "r", "omega.b")

\# Palhs for OpenBUGS and output files

BUGSpath=".../OpenBUGS.exe"

outpath=".../NCSC"

\# RBUGS simulation

data.sim <- rbugs (data=pd342_data, inits, paramSet=parameters, model="342model.txt", bugs=BUGSpath, n.chains $=1$, n.iter $=150000$, bugsWorkingDir=outpath) 
Below is the OpenBUGS code, invoked in R via the file " 342 model.txt":

model

for $(\mathrm{i}$ in $1: \mathrm{N})$

I

mul [i] <- b[ID[i],1] + alphal*x1 [i] + alpha2*x2[i] + alpha3*x3[i] + alpha4*x4[i] + alpha5*x5[i]

+ alpha6*x6[i];

mu2[i] <- b[ID [i],2]+beta $1 * x 1[i]+$ beta $2 * x 2[i]+$ beta $3 * x 3[i]+$ beta $4 * x 4[i]+$ beta $5 * x 5[i]+$ beta $6^{*} \times 6[\mathrm{i}]$;

ones[i] $<-1$;

ones[i] $\sim \operatorname{dbern}(\mathrm{p}[\mathrm{i}])$;

pl $[\mathrm{i}]<-\operatorname{phi}(-\mathrm{mul}[\mathrm{i}])$;

p2[i] <- sqrt(taue)* pow $((y[i]+\operatorname{equals}(y[i], 0)),-1) * \exp \left(-\operatorname{taue}{ }^{*}\right.$ pow $(\log (y[i]+$ equals $(y[i], 0))-m u 2[i], 2) / 2)$;

I

$\mathrm{p}[\mathrm{i}]<-($ equals $(y[\mathrm{i}], 0) * \mathrm{p} 1[\mathrm{i}]+(1-\operatorname{equals}(\mathrm{y}[\mathrm{i}], 0)) * \mathrm{p} 2[\mathrm{i}] *(1-\mathrm{pl}[\mathrm{i}])) / 1000000$;

for ( $\mathrm{i}$ in $1: \mathrm{M}$ )

1

mu.b $[\mathrm{i}, 1]<-$ alpha0;

mu.b $[i, 2]<-$ beta 0 ;

$b[i, 1: 2] \sim d m n o r m(m u . b[i, 1: 2]$, omega.b[1:2,1:2]);

)

itaue $<-1 /$ taue

\# Adapted from Yang EO Berger (1994)

nd1 $<-\max (\mathrm{z} 1, \mathrm{z} 2)$;

nd $2<-\min (\mathrm{zl}, \mathrm{z} 2)$;

$\mathrm{v}[1,1]<-(1-\mathrm{a} * \mathrm{a}) * \mathrm{nd} 1+\mathrm{a} * \mathrm{a}$ *nd 2 ;

$\mathrm{v}[2,2]<-a^{*} a^{*}$ nd $1+\left(1-a^{*} a\right)^{*}$ nd2;

$\mathrm{v}[1,2]<-\mathrm{a}^{*} \operatorname{sqrt}\left(1-\mathrm{a}^{*} \mathrm{a}\right) *$ (nd1-nd 2 );

$\mathrm{v}[2,1]<-\mathrm{v}[1,2]$;

$r<-v[1,2] /(\operatorname{sqrt}(v[1,1]) * \operatorname{sqrt}(v[2,2]))$;

omega.b $[1,1]<-v[2,2] /(v[1,1] * v[2,2]-v[1,2] * v[2,1])$;

omega.b $[1,2]<--v[1,2] /(v[1,1] * v[2,2]-v[1,2] * v[2,1])$;

omega.b[2,1]<- omega.b[1,2];

omega.b $[2,2]<-v[1,1] /(v[1,1] * v[2,2]-v[1,2] * v[2,1])$;

\#-_Prior distributions

alpha0 $\sim \operatorname{dnorm}(-2.0,1.0 \mathrm{E}-6)$;

alphal $\sim \operatorname{dnorm}(.3,1.0 \mathrm{E}-6)$;

alpha2 $\sim \operatorname{dnorm}(0,1.0 \mathrm{E}-6)$;

alpha3 dnorm $(1.0,1.0 \mathrm{E}-6)$;

alpha4 - dnorm $(0,1.0 \mathrm{E}-6)$;

alpha5 dnorm $(0,1.0 \mathrm{E}-6)$;

alpha6 - dnorm $(0,1.0 \mathrm{E}-6)$;

beta0 - dnorm $(1.0,10.0)$;

betal dnorm $(-.35,10.0)$;

beta $2 \sim \operatorname{dnorm}(0,1.0)$;

beta3 $\sim \operatorname{dnorm}(0,10.0)$;

beta4 $\sim \operatorname{dnorm}(0,10.0)$;

beta5 dnorm $(0,10.0)$;

beta6 - dnorm $(.33,1.0)$;

\# Adapted from Yang $\mathcal{E}$ Berger (1994)

a $\sim \operatorname{dunif}(-1,1)$;

zl - $\operatorname{dgamma}(0.5,100)$;

$\mathrm{z} 2$ - dgamma $(0.5,100)$;

taue $\sim \operatorname{dgamma}(1,0.001)$; 